GNEZDITVENA GOSTOTA LESNE SOVE Strix aluco V URBANIH GOZDOVIH LJUBLJANE (OSREDNJa Slovenija)

\section{Breeding density of the Tawny Owl Strix aluco in urban forests of Ljubljana City (Central Slovenia)}

\section{TJAŠA PrŠin ${ }^{1}$, DARJA KUŠAR ${ }^{2}$, TANJA OBERMAJER ${ }^{3}$,} Al VREZEC ${ }^{4}$

1 Cesta na Brdo 86, SI-1000 Ljubljana, Slovenija, email: tjasa.prsin@gmail.com

2 Univerza v Ljubljani, Veterinarska fakulteta, Inštitut za mikrobiologijo in parazitologijo, Gerbičeva 60, SI-1115 Ljubljana, Slovenija, e-mail: darja.kusar@ vf.uni-lj.si

3 Univerza v Ljubljani, Biotehniška fakulteta, Oddelek za zootehniko, Inštitut za mlekarstvo in probiotike, Groblje 3, SI-1230 Domžale, Slovenija, e-mail: tanja.obermajer@bf.uni-lj.si

4 Nacionalni inštitut za biologijo, Večna pot 111, SI1000 Ljubljana, Slovenija, e-mail: al.vrezec@nib.si

\section{Uvod}

Lesna sova Strix aluco je najpogostejša in najbolj razširjena vrsta sove v Sloveniji (GEISTER 1995). Pogosta je zlasti v nižinah, medtem ko je v višjih legah redkejša (Tome 1996). Živi v polodprtih listnatih in mešanih gozdovih $s$ čistinami, odprti krajini s pogozdenimi površinami, v iglastih gozdovih, pa tudi v bližini človeka (MIKkola 1983). Čeprav gre pretežno za gozdno ptico, je zelo prilagodljiva in jo najdemo celo v večjih mestih, kot so London, Berlin in Rim - povsod, kjer so veliki parki in vrtovi s starimi drevesi (MikKola 1983, KöNIG et al. 1999). Za gnezdenje izbira drevesna dupla ali gnezdilnice, opuščena vejnata gnezda, skalne razpoke, votline in police $\mathrm{v}$ klifih, gnezdi pa tudi na stavbah (Mikкola 1983).

Kot gnezdilka urbanih območij je poznana $\mathrm{v}$ več evropskih mestih (LUNICK et al. 2001, BETLEJA et al. 2007, KraLJ \& KRnJeTA 2015). V Zagrebu je velikost gnezdeče populacije ocenjena na 13-15 parov (Kralj \& Krnjeta 2015), na Poljskem v mestu Glivice na 22-47 parov (Betleja et al. 2007) in v Varšavi na 50-80 parov (LuNICK et al. 2001). V Ljubljani naj bi po zadnjih ocenah gnezdilo 30-60 parov (Tome et al. 2013). Kljub temu pa večina podatkov o lesni sovi izhaja le iz priložnostnih najdb mladičev (VREZEC 2000) ali registracij vrste (MIHELIČ 2005), rezultati podrobnejših sistematičnih popisov pa niso na voljo. $\mathrm{V}$ tem prispevku podajamo rezultate prvih sistematičnih popisov po metodi izzivanja $s$ posnetkom (VREZEC 2003) v ljubljanskih urbanih gozdovih, in sicer na območju Krajinskega parka Tivoli, Rožnik in Šišenski hrib ter na območju Golovca. Ugotovljene gostote smo primerjali z gostotami v neurbanih gozdovih v okolici Ljubljane (Krim), kjer si lesne sove delijo življenjski prostor z drugimi kompetitivnimi vrstami sov (VREZEC \& TOME 2004a).

\section{Območje raziskave in metode dela}

\subsection{Območje raziskave}

Sistematične popise teritorijev lesnih sov smo opravili na območjih Krajinskega parka Tivoli, Rožnik in Šišenski hrib, na Golovcu in na Krimu (slika 1). Krajinski park Tivoli, Rožnik in Šišenski hrib leži v samem središču Ljubljane in na skupni površini $4,6 \mathrm{~km}^{2}$ zajema mestni park Tivoli ter parkovna gozdova Rožnik in Šišenski hrib. Območje je bilo razglašeno za krajinski park z odlokom leta 1984, tako zaradi naravnih kot kulturnih vidikov. Osrednji del krajinskega parka $\left(2,9 \mathrm{~km}^{2}\right)$ je razgibano gozdno območje $s$ petimi vzpetinami (Šišenski hrib, Rožnik, Cankarjev vrh, Tivolski vrh in Debeli hrib). V vzhodnem delu je 43 ha velik park Tivoli, ki je primer oblikovane narave. $S$ treh smeri (sever, jug in vzhod) območje povsem omejujejo pozidane površine, le na zahodni strani se povezuje s širšim zaledjem Polhograjskega hribovja, ta ekološki koridor pa preseka trasa zahodnega dela ljubljanske obvoznice. Vzpeti del Krajinskega parka Tivoli, Rožnik in Šišenski hrib po večini porašča samoniklo gozdno rastlinje, ki ga sestavljajo kisloljubni gozdovi gradna Quercus petraea in pravega kostanja Castanea sativa, gozd bukve Fagus sylvatica z rebrenjačo Blechnum spicant ter gozd rdečega bora z borovnico Vaccinio myrtilli-Pinetum 
sylvestris. Med drevesnimi vrstami so najštevilčnejše smreka Picea abies, rdeči bor Pinus sylvestris, bukev, graden, dob Quercus robur, pravi kostanj in črna jelša Alnus glutinosa (SMreKar et al. 2011).

Golovec $\left(8,6 \mathrm{~km}^{2}\right)$ je priljubljeno ljubljansko sprehajališče in prostor za rekreacijo, ki je prepreden s številnimi gozdnimi potmi. Najvišji vrh Mazovik (450 m n.v.) je nadaljevanje Šišenskega hriba in Grajskega griča ter sestavni del litijske antiklinale oziroma Posavskega hribovja (slika 1$)$. V večini $(6,8$ $\mathrm{km}^{2}$ ) je pokrit z gozdom (ŽIžEK 2010), v katerem prevladuje združba bukve in praproti rebrenjače Blechno-Fagetum, ki na severovzhodnem delu hriba preide $\mathrm{v}$ gozd rdečega bora in borovničevja (MELIK 1959, VidmaR \& Pirnat spletni vir).

$\mathrm{Za}$ primerjavo gostot $\mathrm{v}$ urbanih gozdovih Ljubljane smo istočasno opravili še popise na Krimu pri Ljubljani, ki je primer neurbanega sklenjenega gozda. Gre za $140 \mathrm{~km}^{2}$ veliko območje z višinskim razponom 290-1107 m n.v. in širokim planotastim delom, ki meji na južni rob Ljubljanskega barja (slika 1). Kar $75 \%$ območja prekriva gozd s prevladujočim dinarskim bukovo-jelovim gozdom Omphalodo-Fagetum s. lat. Dominantne drevesne vrste so bukev, jelka Abies alba in smreka, večinoma pa gre za starejše, a gospodarjene sestoje (FURLAN 1988, VREZEC 2003).

\subsection{Popisne metode}

Za popis sov smo uporabili metodo s poslušanjem spontanega oglašanja in izzivanja s posnetkom samčeva oglašanja (angl. playback method) (REDPATH 1994), ki temelji na točkovni metodi popisovanja (VREZEC 2003). Za oceno gostote smo na območju Krajinskega parka Tivoli, Rožnik in Šišenski hrib ter Golovca določili 11 točk, na območju Krima pa 62 (v letu 2002) in 25 (v letu 2016), ki so bile med seboj oddaljene približno 1 $\mathrm{km}$ (Zuberogoitia \& Climent 2000).

Popis lesne sove smo opravili v spomladanskem obdobju med marcem in majem v letu 2002 na Golovcu in v letu 2016 v Krajinskem parku Tivoli, Rožnik in Šišenski hrib, v obeh letih pa vzporedno tudi na Krimu. S popisom smo začeli ob mraku, ko so ptice pevke nehale peti (okoli 21. ure), in končali okrog 2. ure ponoči. Popisovali smo ob jasnem in ne preveč vetrovnem vremenu, in sicer na vsaki točki tako, kot je opisano v VREZEC (2003), le s to

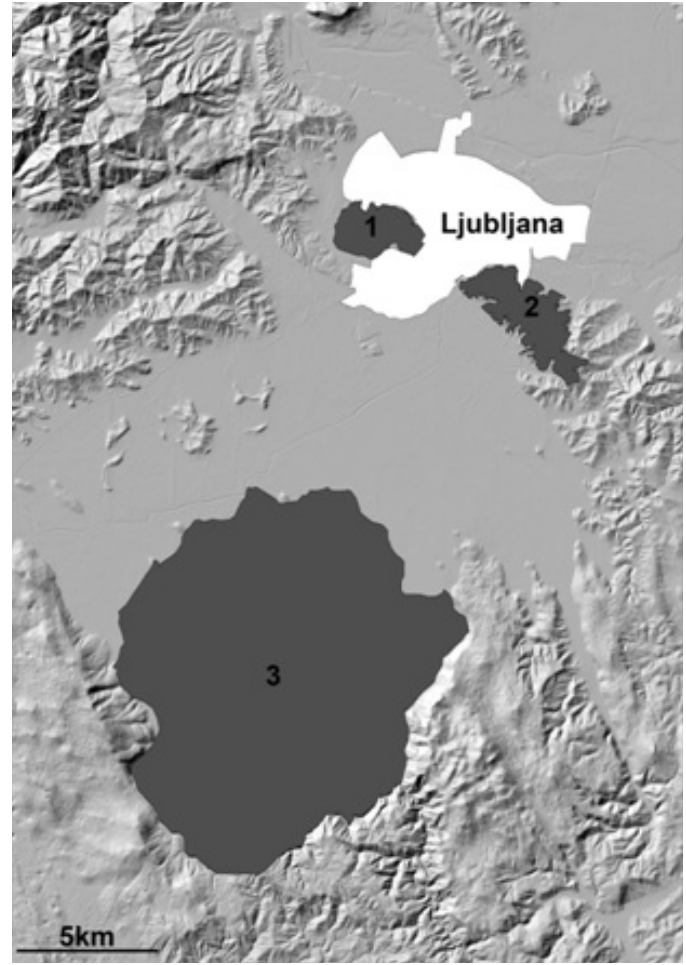

Slika 1: Popisna območja za lesno sovo Strix aluco v Ljubljani in okolici: 1 - Krajinski park Tivoli, Rožnik in Šišenski hrib, 2 - Golovec in 3 - Krim. Z belo površino je označeno urbanizirano območje Ljubljane (karta: Andrej Kapla).

Figure 1: Survey areas of Tawny Owl Strix aluco in the city of Ljubljana and its surrounding: 1 - Tivoli, Rožnik and Šišenski hrib Nature Park, 2 - Golovec, and 3 - Mt. Krim. White area denotes the urbanized area of Ljubljana City (map: Andrej Kapla).

razliko, da smo začeli s 5-minutnim poslušanjem spontanega oglašanja. Če so se ptice odzvale že med samim predvajanjem posnetka, smo posnetek ustavili in teritorij šteli za zasedenega.

Gostoto sovjih teritorijev smo preračunavali po točkah oziroma na območju s polmerom 500 m okrog vsake popisne točke (VREZEC 2003). Predpostavili smo, da vsak odgovor na popisni točki ponazarja zaseden teritorij. Sove, ki smo jih slišali, a so bile od popisne točke oddaljene več kot $500 \mathrm{~m}$, smo iz izračuna ocene gostote izpustili. Obstoj dveh sovjih teritorijev na eni popisni točki je bil zabeležen le, če sta se odzvala dva samca hkrati. 
Na točkah, kjer v prvi noči popisa ni bilo odziva, smo popis ponovili v drugi noči.

Ker je $\mathrm{z}$ uporabljeno metodo predvajanja posnetka teritorialnega oglašanja samca praktično nemogoče ločiti med gnezdečimi in negnezdečimi pari ter zaznati teritorialne nesparjene osebke (VREZEC 2003), so rezultati gostote predstavljeni kot število zasedenih teritorijev / $10 \mathrm{~km}^{2}$ in ne kot število gnezdečih parov. Primerjave gostot oziroma frekvence zasedenosti popisnih točk $s$ teritoriji lesne sove smo ovrednotili s $\chi^{2}$-testom.

\section{Rezultati}

V letu 2002 smo na Krimu zabeležili 28, na Golovcu pa 8 teritorijev lesnih sov. Na območju Krajinskega parka Tivoli, Rožnik in Šišenski hrib smo v letu 2016 zabeležili 9, na Krimu pa 8 teritorijev lesnih sov (tabela 1).

$\mathrm{V}$ urbanih gozdovih smo ugotovili višje gostote teritorijev lesne sove kot pa v neurbanih (tabela 1), vendar razlike $\mathrm{v}$ gostotah niso bile statistično značilne v nobenem od obravnavanih let $\left(\chi^{2}=0,86-\right.$ $2,46, \mathrm{~ns})$.

\section{Diskusija}

$\mathrm{Na}$ širšem območju Ljubljane je $62 \mathrm{~km}^{2}$ gozdnih površin (Tome et al. 2013). Tako lahko na podlagi izračunanih gostot $\mathrm{v}$ urbanih gozdovih podamo oceno velikosti populacije lesnih sov za celotno Ljubljano, med 57 in 65 parov, kar je v rangu ocene iz Tome et al. (2013).
Lesna sova je na gnezdenje v urbanih gozdovih očitno dokaj prilagodljiva vrsta (VREZEC \& TOME 2004b, KöNIG \& WeICK 2008). Urbane razmere lahko na vrsto vplivajo celo pozitivno $\mathrm{z}$ večjo razpoložljivostjo hrane in milejšimi klimatskimi razmerami, kar se lahko pokaže tudi v zgodnejšem gnezdenju (VRezec 2000). Solonen \& URSIN (2008) sta v Helsinkih in okolici ugotovila, da stopnja urbanizacije ne vpliva na populacijsko gostoto in gnezditveno uspešnost lesnih sov. V naši raziskavi v ljubljanskih mestnih gozdovih sicer nismo potrdili, da so gostote lesne sove statistično značilno različne, čeprav so bile skoraj dvakrat večje od neurbanih, kar je verjetno posledica manjšega števila točk. Zanesljivo pa bi lahko višje gostote potrdili z večletnim spremljanjem urbane populacije. Gnezditvene gostote lesne sove so bile po Evropi ugotovljene v zelo širokem razponu od 0,7 do 25,0 teritorija / $10 \mathrm{~km}^{2}$ (VREZEC 2003), zato bi bilo v primeru urbanih gozdov, ki navadno obsegajo majhne površine, treba preveriti, v kakšni meri se gostote spreminjajo med leti. Tako bi bilo mogoče bolj zanesljivo oceniti gostotne razlike med urbanimi in neurbanimi populacijami.

Glavni plen lesne sove so voluharice in miši, vrsta pa ima sicer širok spekter alternativnega plena (KöNIG et al. 1999). Ker je vrsta prehranski generalist, lahko svojo prehrano prilagodi glede na razpoložljivost različnih vrst plena $\mathrm{v}$ okolju (Grzdezicka et al. 2013). Prehrana urbanih lesnih sov v primerjavi z neurbanimi vsebuje večji delež ptic pevk (GAleotTi et al. 1991). Da se delež ptic $\mathrm{v}$ prehrani sov v mestnem okolju povečuje, delež

Tabela 1: Gostote teritorijev lesne sove Strix aluco na izbranih urbanih in neurbanih območjih v Ljubljani in okolici

Table 1: Territory densities of Tawny Owl Strix aluco in the surveyed urban and non-urban areas

\begin{tabular}{|c|c|c|c|c|}
\hline $\begin{array}{l}\text { Leto/ } \\
\text { Year }\end{array}$ & $\begin{array}{l}\text { Območje popisa/ } \\
\text { Survey area }\end{array}$ & $\begin{array}{l}\text { Št. popisnih točk/ } \\
\text { Number of survey points }\end{array}$ & $\begin{array}{l}\text { Št. zabeleženih teritorijev/ } \\
\text { Number of occupied } \\
\text { territories }\end{array}$ & $\begin{array}{l}\text { Gostota } \\
\left(\text { teritoriji / } 10 \mathrm{~km}^{2}\right) / \\
\text { Owl density } \\
\left(\text { territories } / 10 \mathrm{~km}^{2}\right)\end{array}$ \\
\hline 2002 & Krim & 62 & 28 & 5,8 \\
\hline 2002 & Golovec & 11 & 8 & 9,3 \\
\hline 2016 & Krim & 25 & 8 & 4,1 \\
\hline 2016 & $\begin{array}{l}\text { Krajinski park } \\
\text { Tivoli, Rožnik in } \\
\text { Šišenski hrib }\end{array}$ & 11 & 9 & 10,4 \\
\hline
\end{tabular}


malih sesalcev in dvoživk pa zmanjšuje, so potrdili tudi GoszczyŃsKi et al. (1993). Ravno številčnost plena pa določa pojavljanje in gostoto populacije lesne sove, zato sklepamo, da so na območju urbanih gozdov gostote malih sesalcev, ki so glavni vir hrane lesne sove, visoke. Raziskave, s katerimi bi ocenili gostote malih sesalcev na Golovcu in Krajinskem parku Tivoli, Rožnik in Šišenski hrib ter njihov delež v prehrani lesne sove, še niso bile opravljene. Ti podatki bi bili za razumevanje razvoja in prilagajanja urbane populacije lesne sove ključni.

Rezultati naših popisov kažejo na pomembnost zaplat gozdov v urbanem okolju, kjer lahko populacije glodavcev lokalno dosežejo zelo visoke gostote (Adler \& TANner 2013). Poleg tega, da gozd ljudem pomeni mesto za rekreacijo, je tudi pomemben habitat za vrste, kot je lesna sova, ki lahko tudi v urbanem okolju dosegajo visoke populacijske gostote.

\section{Zahvala}

Za pomoč pri popisih območja Krajinskega parka Tivoli, Rožnik in Šišenski hrib se najlepše zahvaljujemo Branku Pršinu. Za izdelavo karte popisnih območij se zahvaljujemo Andreju Kapli.

\section{Povzetek}

$\mathrm{V}$ prispevku podajamo rezultate popisov teritorijev lesne sove Strix aluco v urbanih gozdovih Ljubljane, Krajinskega parka Tivoli, Rožnik in Šišenski hrib ter Golovca, ki smo jih primerjali z gostoto v neurbanem gozdu na Krimu v bližini Ljubljane. Popisovali smo $\mathrm{z}$ uporabo metode izzivanja $\mathrm{s}$ posnetkom samčevega oglašanja spomladi 2002 in 2016. $\mathrm{Na}$ Golovcu smo ugotovili gostoto 9,3 teritorija / $10 \mathrm{~km}^{2}$, v Krajinskem parku Tivoli, Rožnik in Šišenski hrib pa 10,4 teritorija / $10 \mathrm{~km}^{2}$, kar je več kot na Krimu $\left(4,1-5,8\right.$ teritorija $\left./ 10 \mathrm{~km}^{2}\right)$, čeprav razlike med območji niso bile statistično značilne. Na podlagi dobljenih gostot ocenjujemo, da na območju Ljubljane gnezdi med 57 in 65 parov lesnih sov. Lesna sova je glede na gnezdenje v urbanih gozdovih dokaj prilagodljiva vrsta, rezultati naših popisov pa kažejo na pomembnost zaplat gozdov v urbaniziranem okolju.

Ključne besede: lesna sova, Strix aluco, Rožnik, Krim, Golovec, popis, metoda izzivanja s posnetkom oglašanja

\section{Summary}

Results of the survey carried out in the territories of Tawny Owl Strix aluco in Ljubljana urban forests (Tivoli, Rožnik and Šišenski hrib Nature Park and Golovec Hill) were compared with the species territory density in non-urban forest of Mt. Krim. Surveys were performed with the point count method using playback in the springs of 2002 and 2016. The density established at Golovec Hill was 9.3 territories / $10 \mathrm{~km}^{2}$, while in Tivoli, Rožnik and Šišenski hrib Nature Park it reached 10.4 territories $/ 10 \mathrm{~km}^{2}$, which was higher than at Mt. Krim (4.1-5.8 territories / $\left.10 \mathrm{~km}^{2}\right)$, although densities between sites were not statistically different. Based on our surveys, the estimated population size of the urban Tawny Owl in Ljubljana would consist of 57 to 65 pairs. Our results suggest that the Tawny Owl can adapt well to the living conditions in the city urban forests and indicate the importance of the forest patches in urban areas.

Key words: Tawny Owl, Strix aluco, Rožnik, Krim, Golovec, survey, playback method

\section{Literatura}

Adler F. R., TANner C. J. (2013): Urban Ecosystems. Cambridge University Press, Cambridge.

Betleja J., Cempulik P., Chrul Z., Grochowski T., Ostański M., Schneider G., SZlama D. (2007): Atlas of the breeding birds of Gliwice: distribution and numbers in the period 1988-1990. - Annals of the Upper Silesian Museum in Bytom, Natural History No. 17.

FurLAN I. (1988): Primerjalne raziskave zoocenoz karabidov (Carabidae, Coleoptera) $\mathrm{v}$ različnih variantah rastlinske združbe Abieti-Fagetum dinaricum. Diplomsko delo. - Univerza v Ljubljani, Biotehniška fakulteta, VTO za biologijo.

Galeotti P., Morimando F., Violani C. (1991): Feeding ecology of the Tawny Owls (Strix aluco) in urban habitats (northern Italy). - Bollettino di zoologia 58 (2): 143-150.

GeIster I. (1995): Ornitološki atlas Slovenije. - DZS, Ljubljana.

GoszczyŃski J., Jabıonski P., Lesiński G., Romanowski J. (1993): Variation in diet of Tawny Owl Strix aluco L. along an urbanization gradient. Acta ornitologica 27 (2): 113-123.

König C., Weick F., Becking J. H. (1999): Owls: A Guide to the Owls of the World. - Yale University Press. 
König C., Weick W. (2008): Owls. A guide to the owls of the World. Second edition. - Christopher Helm, London.

Kralj J., Krnjeta D. (2015): Atlas ptica gnjezdarica grada Zagreb. - Hrvatska agencija za okoliš i prirodu, Zagreb.

Luniak M., KozŁowski P., Nowicki W., Plit J. (2001): Atlas Warszawy. - Warszawa IGiPZ PAN, Warszawa.

Melik A. (1959): Posavska Slovenija. - Slovenska matica, Ljubljana.

MinELIČ T. (2005): Inventarizacija ptic v krajinskem parku Tivoli, Rožnik in Šišenski hrib. Zaključno poročilo - Društvo za opazovanje in preučevanje ptic Slovenije, Ljubljana.

Mikкola H. (1983): Owls of Europe. - T. \& AD Poyser, London.

Redpath S. M. (1994): Censusing tawny owls Strix aluco using imitation calls. - Bird Study 41 (3): 192-198.

SMrekar A., Erhartič B., Šmid Hribar M. (2011): Krajinski park Tivoli, Rožni in Šišenski hrib. Založba ZRC, Ljubljana.

Tome D. (1996): Višinska razširjenost sov v Sloveniji. Acrocephalus 17 (74): 2-3.

Tome D., Vrezec A., Bordjan D. (2013): Ptice Ljubljane in okolice. - Mestna občina Ljubljana, Ljubljana.

Vidmar B. A., Pirnat B.: Gozdna učna pot Golovec. [http://www2.arnes.si/ opoljanelj/projekti/ gozdna_pot/index-gup.htm], 28/12/2016.

VREZEC A. (2003): Breeding density and altitudinal distribution of the Ural, Tawny, and Boreal owls in North Dinaric Alps (Central Slovenia). - Journal of Raptor Research (37) 1: 55-62.

VReZEC A. (2000): Zgodnje gnezdenje lesne sove (Strix aluco) blizu urbanega središča Ljubljane. Acrocephalus 21 (98/99): 81-82.

VRezec A., Saveljić D. (2006): Breeding density of Tawny Owl Strix aluco territories in montane forests of Mountain Bjelasica (Montenegro). - Ciconia 14: 41-47.

VReZeC A., Tome D. (2004a): Altitudinal segregation between Ural Owl Strix uralensis and Tawny Owl $S$. aluco: evidence for competitive exclusion in raptorial birds. - Bird Study 51: 264-269.

Vrezec A., Tome D. (2004b): Habitat selection and patterns of distribution in a hierarchic forest owl guild. - Ornis Fernica 81: 109-118.

Zuberogoitia I., Martinez Climent J. A. (2000): Methods for Surveying Tawny Owl Strix aluco Populations in Large Areas. - Biota 1 (2): 79-88.

ŽıžEK L. (2010): Odnos javnosti do gozdov v mestih na primerih Rožnika in Golovca v Ljubljani. Diplomsko delo. - Univerza v Ljubljani, Biotehniška fakulteta, Oddelek za gozdarstvo in obnovljive vire. 